\title{
ACCESSING INDIANA'S RIGHT-TO-TRY LAW: IS IT ENOUGH TO EXPAND ACCESS FOR TERMINALLY ILL PATIENTS?
}

\author{
Victoria Howard*
}

\section{TABLE OF CONTENTS}

I. EXPERIMENTAL DRUGS: ACCESS OPTIONS FOR THE TERMINALLY ILL ..................................................271

A. Clinical Trials ......................................................272

B. FDA's Compassionate Use Form (Expanded Access) ..................................................................275

C. New Draft Guidance to Streamline Expanded Access Process ..................................................279

II. THE RIGHT-TO-TRY ....................................................281

A. Is there a Right-to-Try to Save One's Own Life? 281

B. Opponents of Right-to-Try .................................284

1. Impact on Drug Production ...........................284

2. Differences Between Expanded Access Requests and Right-to-Try..........................................285

III. INDIANA's RIGHT-TO-TRY LAW ..............................289

A. Other States on Right-to-Try ...............................291

1. Colorado ....................................................292

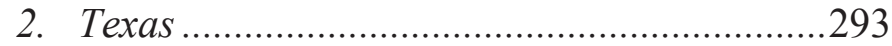

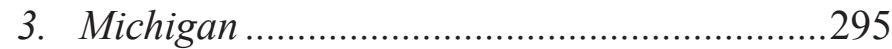

4. Illinois ............................................................296

B. How Does Indiana Compare? ............................297

IV. LiMITATIONS ON RIGHT-TO-TRY.................................301

A. Drug Manufacturers Are Not Required to Provide Patient Access .........................................................301

B. Insurance Companies Are Not Required to Cover, or Contribute to, the Cost of the Experimental

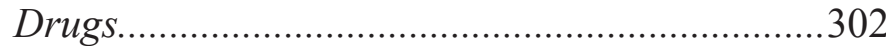

* J.D. Candidate, 2017, Indiana University Robert H. McKinney School of Law; B.A., 2014, Butler University.

http://doi.org/10.18060/3911.0040 


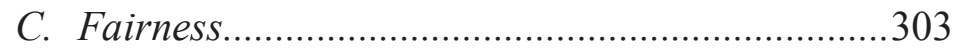

D. Possibility of Federal Preemption ........................304

V. FEDERAL Right-TO-TRY LEGiSlation .......................305

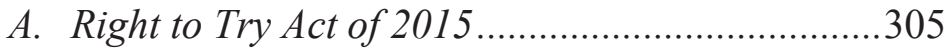

B. Andrea Sloan CURE Act.....................................306

VI. How LimitATIONS WILL IMPACT A PATIENT's RighT-

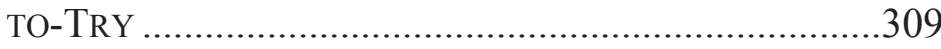

A. Impact on Indiana Patients ..................................310

B. Hope for Future Expansion in access through Federal Legislation ................................................311

C. What if Federal Legislation Fails? .......................312

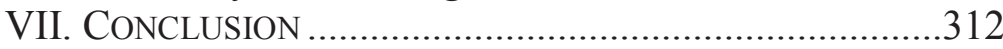

There is new hope for terminally ill patients who wish to gain access to experimental drugs and treatments that could potentially save or prolong their lives. Right-to-try laws have been sweeping the nation, with twenty-four states having passed legislation as of January of 2016. ${ }^{1}$ Indiana passed its own right-to-try law on March 24, 2015. ${ }^{2}$ These laws offer hope to terminally ill individuals seeking access to

${ }^{1}$ About Right to Try, RIGHTTOTRY.ORG, http://righttotry.org/aboutright-to-try/ [https://perma.cc/42EE-BQL9] (last visited March 4, 2016); Right to try states include: Alabama, Arizona, Arkansas, Colorado, Florida, Illinois, Indiana, Louisiana, Michigan, Minnesota, Mississippi, Missouri, Montana, Nevada, North Carolina, North Dakota, Oklahoma, Oregon, South Dakota, Tennessee, Texas, Utah, Virginia, and Wyoming. After this note was written, but prior to publication, nine more states passed right-to-try legislation, including: California, Connecticut, Georgia, Idaho, Maine, New Hampshire, Ohio, South Carolina, and West Virginia.

2 Jessica Firger, Indiana Governor Signs "Right to Try" Drug Law, CBS NEws (March 24, 2015, 5:49 PM), http://www.cbsnews.com/news/indiana-governor-signs-right-to-trydrug-law/ [https://perma.cc/L35D-GUSZ]; H.B. 1065, $119^{\text {th }}$ Gen. Assemb., 1st Reg. Sess. (Ind. 2015); Ind. Code Ann. § 16-42-26-2 (2015); Ind. Code Ann. § 25-22.5-1-2.1 (2017). 
experimental drugs. "Patients who are terminally ill and who are facing less than one year of life expectancy are willing to take greater risks and endure a higher danger of potential adverse effects than other patients, including taking experimental drugs with unknown risk-benefit ratios." 3 Terminally ill patients may be drawn to these experimental drugs if they have exhausted all other options to try to save their own lives. Opponents of right-to-try laws argue that "[e]xpanding patients' access to investigational agents outside of clinical trials without the FDA's oversight may threaten the structure of the research and approval process in the United States." ${ }^{4}$ However, individual patient stories have been very compelling in swaying the legislature in this area ${ }^{5}$ and appear to be beating out the skeptics as evidenced by the growing number of state right-to-try laws taking effect. ${ }^{6}$

Indiana's right-to-try law offers hope of expanded access to the terminally ill within the state of Indiana. However, the state law itself is unlikely to achieve its goal of expanded access. ${ }^{7}$ State right-to-try laws are generally expected to face legal issues, such as possible federal preemption, that may make it challenging for state laws to be successful in expanding access to experimental drugs to the terminally ill. ${ }^{8}$ However, as of yet, the U.S. Food and Drug Administration ("FDA") has not challenged this limitation in federal court. In addition to this possible major limitation, Indiana's law

3 Y. Tony Yang et al., "Right-to-Try" Legislation: Progress or Peril?, 33 J. ClinicAl OnCOLOGY 2597, 2597 (August 20, 2015).

${ }^{4} I d$. at 2598.

5 Rebecca Dresser, The "Right to Try" Investigational Drugs: Science and Stories in the Access Debate, 93 TEX. L. REV. 1631, 1631 (2015).

${ }^{6}$ About Right to Try, supra note 1.

7 Nathaniel Weixel, State Right-to-Try Laws for Experimental Therapies Popular, but Effect Minimal, 9 MED. DEVICES LAW \& INDUST. REPORT 186 (March 5, 2015).

${ }^{8} \mathrm{Id}$. 
faces further limitations created by the law's inability to: (1) force drug manufacturers to provide access to the drug, and (2) require insurance companies to pay for the experimental drugs. ${ }^{9}$ Other major concerns include safety, fairness, and the law's effect on the integrity of the research process. ${ }^{10}$

Indiana's right-to-try law is a step in the right direction towards expanding access for terminally ill patients, but due to its limitations, it is likely to fall short of actually being able to expand access. However, hope still remains for expanded access, despite the limitations the law may face. Federal legislation is in the works ${ }^{11}$ and the FDA is in the process of creating a streamlined expanded access program, ${ }^{12}$ both of which could offer hope to terminally ill patients seeking expanded access to experimental drugs.

This Note aims to evaluate Indiana's new right-to-try law to determine how effective it will likely be in expanding patients' access to investigational drugs. Part I of this Note discusses other avenues, besides right-to-try, that patients currently have for seeking access to experimental drugs. This section explains why these approaches are too limited and why right-to-try is needed. Part II discusses the most significant case in regards to expanded access, Abigail Alliance for Better Access v. Von Eschenbach, to help provide a history of what began the right-to-try movement. This case is important because it discusses whether terminally ill patients may have a fundamental right to save their own lives. ${ }^{13}$ This section also explains the position of

\footnotetext{
${ }^{9}$ Ind. Code $\S 25-22.5-1-2.1$ (2017).

${ }^{10}$ Weixel, supra note 7.

${ }^{11}$ H.R. 3012, $114^{\text {th }}$ Cong. (2015-2016).

12 Expanded Access (Compassionate Use), U.S. FOOD \& DRUG ADMIN., http://www.fda.gov/NewsEvents/PublicHealthFocus/ExpandedAccessC ompassionateUse/default.htm [https://perma.cc/L7KE-SRDB] (last updated Jan. 18, 2017).

${ }^{13}$ See generally Abigail All. for Better Access to Developmental Drugs v. von Eschenbach, 495 F.3d 695 (D.C. Cir. 2007).
} 
opponents of right-to-try to provide a well-rounded foundation on the issue. Part III of this Note closely examines Indiana's right-to-try law and also discuss what other states are doing. Part IV will evaluate the limitations that Indiana and other states will face in implementing their right-to-try laws. Part V explains possible federal legislation that could cure the limitation of federal preemption. Part VI argues that these limitations will greatly impact the ability of Indiana, and other state laws, from actually expanding access to the terminally ill. Finally, this Note provides suggestions for other avenues of hope for expanded access.

\section{EXPERIMENTAL DRUgS: ACCESS OPTIONS FOR THE TERMINALLY ILL}

The FDA currently regulates the drug approval process but allows two controlled options for unapproved drugs outside of the right-to-try. ${ }^{14}$ However, these two options have limitations, and the right-to-try may be a better option for terminally ill patients. Patients, who have exhausted their conventional treatment options, may utilize these exceptions to gain access to potentially life-prolonging investigational drugs that have not yet reached final approval by the FDA. ${ }^{15}$ The first option for patients is entering a clinical trial. ${ }^{16}$ Clinical trials "test potential treatments in human volunteers to see whether they should be approved for wider use in the general population." 17 The clinical trial process is important to understand in order to have an appreciation for the

\footnotetext{
${ }^{14}$ Yang et al., supra note 3, at 2597.

${ }^{15} \mathrm{Id}$.

${ }^{16} I d$.

17 Conducting Clinical Trials, U.S. Food \& DRUG ADMIN., http://www.fda.gov/drugs/developmentapprovalprocess/conductingclini caltrials/default.htm [https://perma.cc/APT9-VWHS] (last updated
} Sept. 2, 2014). 
struggles terminally ill patients may face and why these two controlled options may make the right-to-try a better opportunity for many patients.

The second option is the FDA's compassionate use form, also referred to as an expanded access request, which allows patients to have their situation reviewed, "on a case-by-case basis," to determine if they should be allowed access to treatments outside of the clinical trial process. ${ }^{18}$ Additionally, new draft guidance is in the works that may help to streamline the FDA's compassionate use process. ${ }^{19}$ While compassionate use does help to expand access, its limitations must be acknowledged in order to get a better idea of the challenges terminally ill patients face without the right-to-try.

\section{A. Clinical Trials}

Clinical trials represent one way patients are able to gain access to experimental drugs before they reach final approval and are used to test potential treatments before they are approved for wide spread use. ${ }^{20}$ "A treatment could be a drug, medical device, or biologic." ${ }^{21}$ Before a clinical trial can begin, the drug developer must file an Investigational New Drug Application ("IND") to be reviewed by the FDA and a local institutional review board ("IRB"). If approved, the drug can move into clinical trials with human participants. ${ }^{22}$ Prior to this approval stage, these drugs must

\footnotetext{
${ }^{18}$ Weixel, supra note 7.

${ }^{19}$ Expanded Access (Compassionate Use), supra note 12.

${ }^{20}$ Conducting Clinical Trials, supra note 17.

${ }^{21} \mathrm{Id}$.

${ }^{22}$ The FDA's Drug Review Process: Ensuring Drugs Are Safe and Effective, U.S. FOOD \& DRUG ADMIN., http://www.fda.gov/drugs/resourcesforyou/consumers/ucm143534.htm [https://perma.cc/C75X-ARPR] (last updated Nov. 6, 2014).
} 
go through preclinical testing, often with the use of laboratory animals. ${ }^{23}$

Before a drug can go on the market, the FDA must make a determination of whether the drug developer's proposal for human testing is reasonably safe. ${ }^{24} \mathrm{Next}$, the drug developer must get IRB approval, which requires a description of the type of people who will participate, the schedule for tests and procedures the participants will undergo, objectives, and other important details of the study. ${ }^{25}$ After approval, the drug will begin clinical trials, consisting of three phases. ${ }^{26}$

During Phase One, the goal will be to determine frequent side effects that the drug may cause and how the drug is metabolized and excreted. ${ }^{27}$ This phase will normally utilize twenty to eighty participants who are healthy volunteers. ${ }^{28}$ The main emphasis in this phase is on safety. ${ }^{29}$ If Phase 1 does not reveal any unacceptable toxicity in the drug, then it may proceed to Phase $2 .^{30}$

Phase 2 emphasizes the effectiveness of the drug and has the goal of preliminarily determining if the drug is working for those with a certain disease or condition. ${ }^{31}$ Placebo groups are often used during this phase, usually with between a few dozen to 300 participants. ${ }^{32}$ If the drug demonstrates evidence of effectiveness, the drug will move forward to Phase 3 of testing. ${ }^{33}$
${ }^{23} I d$.
${ }^{24} I d$.
${ }^{25}$ Id.
${ }^{26} I d$.
${ }^{27}$ Id.
${ }^{28} I d$.
${ }^{29} \mathrm{Id}$.
${ }^{30} \mathrm{Id}$.
${ }^{31} \mathrm{Id}$.
${ }^{32}$ Id.
${ }^{33} I d$. 
In Phase 3, further data on safety and effectiveness are gathered within different populations and with different dosages of the drug. ${ }^{34}$ The drug is also tested in combination with other drugs. ${ }^{35}$ This phase usually utilizes several hundred to 3000 participants. ${ }^{36}$ If the drug successfully makes it through these three phases, the drug developer may then file a New Drug Application ("NDA") with the FDA and wait for final approval. ${ }^{37}$

Clinical trials are vital to the current drug approval process, but they may not be enough to expand terminally ill patients' access to experimental drugs because they are not an option for many patients. ${ }^{38}$ Patients may be unable to join a clinical trial for a number of reasons, such as their geographical location, stringent eligibility criteria required of participants, or due to timing of the trial. ${ }^{39}$ Additionally, clinical trials often only allow a limited number of patients to participate. ${ }^{40}$ Patients with end-stage diseases are also at a disadvantage because the objective of a clinical trial is "to monitor a drug's long-term effects;" therefore, healthy participants are often a better choice. ${ }^{41}$ Often times, patients who are the sickest are barred from participating in a trial. ${ }^{42}$

\footnotetext{
${ }^{34} \mathrm{Id}$.

${ }^{35} \mathrm{Id}$.

${ }^{36} \mathrm{Id}$.

${ }^{37} \mathrm{Id}$.

${ }^{38}$ Expanded Access (Compassionate Use), supra note 12.

${ }^{39}$ M.E. Blair Holbein et al., Access to Investigational Drugs: FDA Expanded Access Programs or "Right-to-Try" Legislation?, 8 CTS J., 526, 528 (2015).

${ }^{40}$ Marisa A. Trasatti \& Sarah M. Grago, To Try or Not to Try: Who Decides Is the Question, 64 FDCC Q. 311, 318 (2015) http://www.semmes.com/publications_archive/litigation/pdf/to-try-ornot.pdf [https://perma.cc/N27E-S8L5].

${ }^{41} \mathrm{Id}$.

${ }^{42}$ Everyone Deserves the Right to Try: Empowering the Terminally Ill to Take Control of Their Treatment, GoLDWATER INST. (Feb. 11, 2014), http://goldwaterinstitute.org/en/work/topics/healthcare/right-to-
} 
In fact, approximately $97 \%$ of patients who are the sickest are not eligible for or lack access to clinical trials." 43 Therefore, those patients who are very ill may not qualify for a clinical trial and must seek access to experimental drugs another way.

Additionally, the drug approval process can be very lengthy, taking up to nine years for a drug to go through testing and become available to patients for use. The average time for a drug to become approved is seven years. ${ }^{44}$ Those individuals who are terminally ill do not have this long to wait for a potentially lifesaving drug and could die, or become much sicker, before a critical drug makes its way through these three clinical trial phases and gains approval.

Due to the limitations of clinical trials, the right-to-try may be a better option for the terminally ill. Right-to-try bypasses the lengthy drug approval process and has less stringent eligibility criteria. Therefore, the right-to-try offers patients greater and faster access to experimental treatments then the current clinical trial process.

\section{B. FDA's Compassionate Use Form (Expanded Access)}

The FDA's compassionate use form provides patients another way to access experimental drugs that are still in the development stages, without requiring them to enter a clinical trial. ${ }^{45}$ In the last four years, the FDA accepted 5816 of its 5849 applications for expanded access. ${ }^{46}$ While the FDA approves most applicants, it is preferable that, when

try/everyone-deserves-right-try-empowering-terminally-/

[https://perma.cc/869F-C8CQ].

${ }^{43} \mathrm{Id}$.

${ }^{44}$ Trasatti \& Grago, supra note 40, at 317.

${ }^{45}$ Weixel, supra note 7.

${ }^{46}$ Yang et al., supra note 3, at 2597. 
possible, patients receive medications through a clinical trial. ${ }^{47}$ The FDA prefers clinical trials to generate data, further the drug approval process, and to help provide wider availability of drugs.$^{48}$ However, since some patients are not able to participate in clinical trials, and without right-to-try laws in place to help them obtain experimental drugs, their only option left is expanded access. ${ }^{49}$

For a patient to qualify for expanded access, they must meet four criteria. First, a licensed physician must have decided that the patient has "no other comparable or satisfactory alternative" treatment options, and that the probable risk the patient will incur from the investigational drug is not more than the probable risk from the patient's medical condition. ${ }^{50}$ Second, the drug must be sufficiently safe and effective as to support the use of it as an investigational drug. ${ }^{51}$ Third, the patient's use of the drug cannot interfere with the "initiation, conduct, or completion" of a clinical trial that will support marketing and approval of the drug. ${ }^{52}$ Fourth, a clinical protocol must be submitted by the patient's sponsor, which describes the use of the drug in a single patient situation. ${ }^{53}$ Additionally, the patient needs to understand and accept the risks that are associated with taking an investigational drug. ${ }^{54}$ One of those potential risks includes the unknown effects of the drug the patient will be taking. ${ }^{55}$ Patients are normally required to sign an informed

\footnotetext{
${ }^{47}$ Expanded Access (Compassionate Use), supra note 12.

${ }^{48} \mathrm{Id}$.

${ }^{49}$ See Weixel, supra note 7.

${ }^{50} 21$ U.S.C. $\S 360 \mathrm{bbb}(2015)$.

${ }^{51} \mathrm{Id}$.

${ }_{52}^{52} \mathrm{Id}$.

${ }^{53} \mathrm{Id}$.

${ }^{54}$ Expanded Access (Compassionate Use), supra note 12.

${ }^{55} \mathrm{Id}$.
} 
consent form before they are able to receive the drug to acknowledge they know and accept the risks. ${ }^{56}$

Expanded access may allow some patients the ability to utilize experimental drugs who may not have otherwise been able to gain access to the drug through a clinical trial. However, the process still faces some limitations in its ability to expand access. The process is very lengthy and requires physicians, who are often already overloaded with patients, to complete copious amounts of paperwork. ${ }^{57}$ Even after a physician applies for expanded access, it often takes two to four months for the request to be approved, time terminally ill patients do not have to wait. ${ }^{58}$ However, rightto-try laws aim to accelerate this process by allowing terminal patients to gain access to the experimental drugs they desire more quickly. ${ }^{59}$

The compassionate use process also faces similar limitations of right-to-try laws. ${ }^{60}$ Even if a patient is approved for compassionate use of a drug, the drug manufacturer is not compelled to make their drugs available to that patient. ${ }^{61}$ The drug manufacturer must agree to provide the experimental drug, to be administered by compassionate use, before a patient can receive the drug. ${ }^{62}$ The FDA does not have the power to require that the drug manufacturer provide their drug to the patient, giving drug companies the power to deny a patient's request for expanded access. ${ }^{63}$ Also, no law currently exists to compel

\footnotetext{
${ }^{56} I d$.

${ }^{57}$ See Rita Rubin, Experts Critical of America's Right-To-Try Drug Laws, 386 WORLD REPORT 1325 (October 3, 2015).

${ }^{58}$ Julie A. Jacob, Questions of Safety and Fairness Raised as Rightto-Try Movement Gains Steam, 314 JAMA 758, 758 (2015).

${ }^{59}$ Yang et al., supra note 3, at 2597.

${ }^{60}$ See Weixel, supra note 7.

${ }^{61}$ Expanded Access (Compassionate Use), supra note 12.

${ }^{62} \mathrm{Id}$.

${ }^{63} \mathrm{Id}$.
} 
insurance companies to pay the cost of the experimental drug, or the cost to cover any unexpected side effects from the treatment, even if a patient obtains access through compassionate use. ${ }^{64}$ This leaves the patient responsible for paying for the drug and the medical care associated with its use.

The goal of expanded access is to strike a balance between providing patients with unapproved drugs and protecting them from unreasonable toxicity or danger, while still being able to collect safety data on the drugs that the patients decide to take. ${ }^{65}$ To begin the expanded access process, the patient will need an agreement between the manufacturer of the drug and their treating physician. ${ }^{66}$ The FDA then must authorize these arrangements through an IND Application and oversight by an IRB is also required. ${ }^{67}$ These steps insure that expanded access is highly regulated.

Patients also have the option of emergency INDs, which can be used by a physician in life-threatening circumstances when a patient has no other alternative treatment available to them, and they do not have enough time "to prepare a written submission to the FDA." ${ }^{\prime 6}$ However, emergency INDs are only used in "infrequent and extraordinary situations" but will allow a physician to treat the patient without first

${ }^{64}$ Weixel, supra note 7.

${ }^{65}$ Holbein et al., supra note 39 , at 526.

${ }^{66} \mathrm{Id}$. at 528 .

${ }^{67} \mathrm{Id}$.

${ }^{68}$ Physician Request for an Individual Patient IND under Expanded Access for Non-emergency or Emergency Use, U.S. FOOD \& DRUG ADMIN

http://www.fda.gov/Drugs/DevelopmentApprovalProcess/HowDrugsar eDevelopedandApproved/ApprovalApplications/InvestigationalNewDr ugINDApplication/ucm107434.htm [https://perma.cc/H56F-X4DV] (last updated May 26, 2015) [hereinafter Physician Request for Patient IND]; see also Holbein et al., supra note 39, at 529. 
notifying and getting approval from the FDA. ${ }^{69}$ Still, the physician should make an attempt to make their request via telephone or other means of communication prior to giving the patient the drug. ${ }^{70}$ Emergency treatment may begin without prior IRB approval, but the physician must notify the IRB of the emergency treatment within five working days of administering treatment. ${ }^{71}$ Essentially, an emergency IND would equate to being very similar to utilizing right-totry legislation to access a drug, but the emergency IND maintains oversight and accountability as it still involves the FDA. ${ }^{72}$ While compassionate use and emergency IND's do help to expand a patient's access, they do not make experimental drugs as easily accessible to terminally ill patients as the right-to-try strives to do.

\section{New Draft Guidance to Streamline Expanded Access Process}

Current compassionate use requests must be completed using Form FDA $1571 .{ }^{73}$ However, the FDA is currently

69 Physician Request for Patient IND, supra note 70; see also Holbein et al., supra note 39, at 529.

70 Physician Request for Patient IND, supra note 70; see also Holbein et al., supra note 39, at 529.

71 Physician Request for Patient IND, supra note 70; see also Holbein et al., supra note 39, at 529-30.

${ }^{72}$ Holbein et al., supra note 39, at 530.

73 Expanded Access (Compassionate Use), FDA, http://www.fda.gov/NewsEvents/P

ublicHealthFocus/ExpandedAccessCompassionateUse/default.htm [http://perma.cc/D6E8-3RNM] (Last viewed Oct. 26, 2015); Expanded Access (Compassionate Use), supra note 12. Since writing this note, but prior to publication, the FDA no longer requires Form 1571 for individual patient expanded access to investigational drugs. See also Physician Request for an Individual Patient IND under Expanded Access for Non-emergency or Emergency Use. FDA, https://www.fda.gov/drugs/developmentapprovalprocess/howdrugsared 
drafting an alternative form, FDA 3926. This form will allow licensed physicians to submit requests for individual patient expanded access to investigational drugs, through a much shorter form that is easier to complete. ${ }^{74}$ However, according to Darcy Olsen, the president of the Goldwater Institute, the new draft guidance that the FDA released may be shorter, but the rest of the process the FDA requires to obtain the expanded access will still be in place. ${ }^{75}$ Olsen stated "[r]egrettably, a 'simpler form' is window dressing on an archaic and inhumane system that prevents the vast majority of Americans with terminal illness from accessing promising investigational treatments." still beg the federal government for permission to try to save their own lives-it's just a shorter form." 77

The new form is estimated to take physicians about forty-five minutes to complete, which is much less than the

evelopedandapproved/approvalapplications/investigationalnewdruginda pplication/ucm107434.htm [https://perma.cc/D68P-5VS9] (Last viewed April 6, 2017). Since writing this note, but prior to publication, Form 3926 can now be used by physicians when submitting requests for individual patient expanded access to investigational drugs, including in emergencies. Physicians are still able to use Form 1571 for submissions for single patient expanded access, but Form 3926 is developed specifically for these kinds of requests and should be easier to complete.

${ }^{74} \mathrm{Id}$.

${ }^{75}$ Bronwyn Mixter, FDA Issues Draft Guidance to Streamline Process for Obtaining Investigational Drugs, BloOMBERG BNA Health L. Resource Ctr., 14 Med. Res. L. \& Pol'y Rep. 124 (Feb. 18, 2015), http://healthlawrc.bna.com.proxy.mckinneylaw.uits.iu.edu/hlrc/4252/sp lit_display.adp?fedfid $=63176540 \&$ vname $=$ mrlrnotallissues \&wsn $=4947$ $87000 \&$ searchid $=26005821 \&$ doctypeid $=9 \&$ type $=$ oadate 4 news $\&$ mode $=$ doc\&split $=0 \& \mathrm{scm}=4252 \& \mathrm{pg}=0$. The Goldwater Institute was established in 1988, as an Arizona-based conservative and libertarian public policy think tank.

$$
{ }^{76} \mathrm{Id} \text {. }
$$


100 hours that the current form often takes. ${ }^{78}$ This new streamlined form has the potential to help patients gain access to experimental drugs faster and make it much simpler for physicians to engage in the process. ${ }^{79}$ While this is a step in the right direction for expanding access, it still requires more of a process and more regulation than what right-to-try attempts to offer. Because terminally ill patients lack time, being able to directly access the drug without an application process would make their access even easier. Advocates of right-to-try contend that these two FDA options (discussed above), that allow access to experimental drugs, are therefore not enough. ${ }^{80}$

\section{THE RIGHT-TO-TRY}

\section{A. Is there a Right-to-Try to Save One's Own Life?}

The right to try was first discussed in court in 2006 in Abigail Alliance for Better Access v. von Eschenbach. ${ }^{81}$ The court addressed whether the Constitution provides a right of access to experimental drugs, which have only passed limited safety trials, to patients who are terminally ill. ${ }^{82}$ In the case, the Abigail Alliance was formed after twenty-one year old Abigail Burroughs ran out of conventional options to try and treat her cancer. ${ }^{83}$ Her oncologist knew of new drugs that were very promising for her kind of cancer, and he felt that these drugs had a "significant chance of saving

\footnotetext{
${ }^{78}$ Rubin, supra note 59.

${ }^{79} \mathrm{Id}$.

${ }^{80}$ Trasatti \& Grago, supra note 40, at 324.

81 Abigail All. for Better Access to Developmental Drugs v. von Eschenbach, 495 F.3d 695, 697, 707, 711-12 (D.C. Cir. 2007).

${ }^{82} I d$.

83 Frank Burroughs, Our Story, ABIGAIL AlLIANCE, http://www.abigail-alliance.org/story.php [https://perma.cc/PYB4A4AJ] (last visited Feb. 6, 2016).
} 
her life." ${ }^{84}$ Her father formed the Abigail Alliance for Better Access to Developmental Drugs and brought suit in order to help his daughter gain access to these drugs. The Alliance sought access to potentially life-saving drugs, that had completed Phase One of testing, "on behalf of . . terminally ill adult patients ... who [had] no [other] governmentapproved treatment options" available to them. ${ }^{85}$ They argued that FDA policy violated terminally ill patients' "substantive due process rights to privacy, liberty, and life. . . ." "86 Unfortunately, Abigail passed away before a judgment was reached, and she never gained access to the drugs her oncologist recommended, which were later approved by the FDA. ${ }^{87}$

The Court of Appeals held "there is no fundamental right 'deeply rooted in this Nation's history and tradition' of access to experimental drugs for terminally ill." ${ }^{\circ 8}$ However, the dissent provided strong support for a patient's right to save his or her own life. In his dissent, Judge Rogers states:

[I]t is startling that the oft-limited rights to marry, to fornicate, to have children, to control the education and upbringing of children, to perform varied sexual acts in private, and to control one's own body even if it results in one's own death or the death of a fetus have all been deemed fundamental rights covered, although not always

${ }^{84} I d$.

${ }^{85}$ Abigail All. for Better Access to Developmental Drugs v. von Eschenbach, 445 F.3d 470, 472 (D.C. Cir. 2006), on reh'g en banc sub nom., 495 F.3d 695 (D.C. Cir. 2007).

${ }^{86} \mathrm{Id}$.

${ }^{87}$ Trasatti \& Grago, supra note 40, at 314-15.

${ }^{88}$ Abigail All. for Better Access to Developmental Drugs v. von Eschenbach, 495 F.3d 695, 697 (D.C. Cir. 2007) (quoting Moore v. East Cleveland, 431 U.S. 494, 503 (1977) (plurality opinion)). 
protected, by the Due Process Clause, but the right to try to save one's life is left out in the cold despite its textual anchor in the right to life. This alone is reason the court should pause about refusing to put the FDA to its proof when it denies terminal patients with no alterative therapy the only option they have left, regardless of whether that option may be a long-shot with high risks. ${ }^{89}$

He also reasoned that the court committed a logical error by concluding that experimental drugs are not necessary. ${ }^{90}$ Though the drugs may not cure a terminally ill patient, they are necessary if the patient is to have "any possibility of preserving" their own life. ${ }^{91}$ Without this right-to-try, terminally ill patients have little chance at trying to preserve their lives.

The Supreme Court denied certiorari in $2008,{ }^{92}$ but that does not mean the Court might not hear the issue in the future, leaving the possibility that one day there may be a right-to-try to save one's own life. However, for now, the Court of Appeals decision stands and, to date, no court has recognized a fundamental right to access experimental drugs. ${ }^{93}$ This case is significant because it is the leading case law for the right-to-try.

${ }^{89} \mathrm{Id}$. at 715 (Rogers, J., dissenting) (emphasis added).

${ }^{90} \mathrm{Id}$.

${ }^{91} \mathrm{Id}$.

${ }^{92}$ Abigail All. for Better Access to Developmental Drugs v. von Eschenbach, cert. denied, 552 U.S. 1159, 1159 (2008).

${ }^{93}$ Trasatti \& Grago, supra note 40, at 316. 


\section{B. Opponents of Right-to-Try}

Opponents argue that right-to-try legislation allows a vulnerable population, the terminally ill, to be exposed to unproven treatments and medications that could be dangerous to their health. ${ }^{94}$ They argue that while the laws are well intentioned, there is not enough federal regulation required to ensure that patients are safe and aware of the risks they would be undertaking. ${ }^{95}$

Additionally, opponents of right-to-try argue that terminally ill patients may have unrealistic expectations of the experimental drugs they seek and may not fully understand the adverse side effects they could incur from taking the drug. ${ }^{96}$ While patients argue they have nothing to lose, opponents argue that experimental drugs could shorten the life terminally ill patients have left or could make their remaining life more miserable due to possible adverse side effects. ${ }^{97}$ Opponents caution that it is very important that physicians have a thorough discussion with their patients, "about the potential benefits and risks" of the experimental treatment they are considering. ${ }^{98}$ Additionally, they should also discuss the financial burden that the patient might incur. ${ }^{99}$

\section{Impact on Drug Production}

Drug companies also have an interest in their drugs becoming approved, which could lead to a reluctance to support the right-to-try. Drug companies do not want to

\footnotetext{
${ }^{94}$ Holbein et al., supra note 39 , at 531.

95 Trasatti \& Grago, supra note 40, at 326.

96 Jacob, supra note 60, at 760.

${ }^{97} \mathrm{Id}$. .

${ }^{98} \mathrm{Id}$. at 758 .

${ }^{99} \mathrm{Id}$.
} 
report "negative outcomes or possible unexpected and severe toxicities," as these would have a negative impact on their ability to obtain FDA approval for the drug. ${ }^{100}$ The risk of an adverse outcome is likely too great of a risk for drug companies, and they are more likely to not offer the drug than risk having to report a bad outcome. ${ }^{101}$ Drug companies also have to worry about the label warnings they will be required to put on their drugs, if passed, and the overall marketability and profitability of their drug, which could be greatly impacted by adverse outcomes. ${ }^{102}$ Adverse outcomes might also deter other patients from joining clinical trials for the experimental drug, which could slow the drug approval process. ${ }^{103}$ Therefore, some may argue that the right-to-try could have a great impact, and perhaps a negative one, on the drug production process.

\section{Differences Between Expanded Access Requests and} Right-to-Try

While the FDA's expanded access program and model right-to-try legislation seem very similar, they actually differ in some crucial respects. The FDA's expanded access program was written to help provide patients with an effective way to access investigational drugs, while still maintaining the balance between a patient's safety and access. ${ }^{104}$ Right-to-try legislation tries to speed up the access process by creating loopholes that would allow patients to bypass the federal oversight process and IRB committee review. ${ }^{105}$ The process proposed by right-to-try is in many

\footnotetext{
${ }^{100}$ Yang et al., supra note 3, at 2598.

${ }^{101} \mathrm{Id}$.

102 Id.

${ }^{103} \mathrm{Id}$.

${ }^{104}$ Holbein et al., supra note 39, at 531.

${ }^{105} \mathrm{Id}$.
} 
ways analogous to the FDA's expanded access program except that right-to-try does not include safety precautions and the regulations that the FDA imposes to help protect patients. ${ }^{106}$ Both processes allow patients access to the same drugs, which have completed Phase One of the approval process. ${ }^{107}$

Right-to-try legislation and the expanded access program define investigational drugs somewhat differently. The FDA defines an investigational drug as a "[n]ew drug or biological drug that is used in a clinical investigation." 108 Model right-to-try legislation defines an investigational drug as a "drug, biological product, or device that has successfully completed Phase One of a clinical trial but has not yet been approved for general use by the United States Food and Drug Administration and remains under investigation in a United States food and drug administration-approved clinical trial." 109 The major difference here is that right-to-try requires Phase One of testing to be successfully completed.

Expanded access programs are regulated by the FDA and IRBs, which insure they receive much more oversight than what right-to-try requires. ${ }^{110}$ Right-to-try requires no oversight from any agency or a requirement for independent review prior to a patient receiving an investigational drug. ${ }^{111}$ Under expanded access, a physician must weigh the risk to

106 Trasatti \& Grago, supra note 40, at 325.

107 Id.

${ }^{108}$ Holbein et al., supra note 39, at 527.

109 See Right to Try Model Legislation, GOLDWATER InST., https://goldwater-

media.s3.amazonaws.com/cms_page_media/2015/1/28/RIGHT\%20TO

\%20TRY\%20MODEL\%20LEGISLATTION\%20\%282\%29_1.pdf

[https://perma.cc/JR7R-927Y] (last visited Feb. 6, 2017).

110 See 21 C.F.R. 312 (2016); see also Holbein et al., supra note 39, at 527; see also Right to Try Model Legislation, supra note 107.

${ }^{111}$ See generally 21 C.F.R. 312 (2016); see also Holbein et al., supra note 39 , at 527 
the patient posed by the investigational drug they wish to take, and ensure that the risk is no greater than the probable risk the patient would face from their disease or condition. ${ }^{112}$ However, right-to-try allows a physician to prescribe or recommend an investigational drug after all other currently available treatment options have been considered. ${ }^{113}$ Rightto-try, therefore, gives the patient and the physician more room to decide how much risk the patient is willing to assume.

Additionally, expanded access requires a treatment duration that is usually limited only to a single course of treatment, while right-to-try has no stated limit. ${ }^{114}$ Expanded access also requires much higher accountability than rightto-try, which only requires that the physician obtain the patients' informed consent. ${ }^{115}$ Expanded access requires that a physician obtains IRB approval and informed consent prior to administering a drug (unless emergency IND), and requires the physician to report adverse events, maintain case histories and drug disposition records, after treatment begins. ${ }^{116}$ At the end of treatment, the physician is also required to submit a summary report to the FDA. ${ }^{117}$

Expanded access also sets parameters on how much a manufacturer may charge for an investigational drug, but like right-to-try, there is no requirement that an insurance

112 See 21 C.F.R. 312 (2016); see also Holbein et al., supra note 39, at 527; see also Right to Try Model Legislation, supra note 111.

113 See 21 C.F.R. 312 (2016); see also Holbein et al., supra note 39, at 527; see also Right to Try Model Legislation, supra note 111.

${ }^{114}$ See 21 C.F.R. 312 (2016); see also Holbein et al., supra note 39, at 527; see also Right to Try Model Legislation, supra note 111.

115 See 21 C.F.R. 312 (2016); see also Holbein et al., supra note 39, at 527; see also Right to Try Model Legislation, supra note 111.

116 See 21 C.F.R. 312 (2016); see also Holbein et al., supra note 39, at 527; see also Right to Try Model Legislation, supra note 111.

117 See 21 C.F.R. 312 (2016); see also Holbein et al., supra note 39, at 527; see also Right to Try Model Legislation, supra note 111. 
company or governmental health care program must provide the investigational drug to the patient who requests it. ${ }^{118}$ Liability is also a major concern when dealing with unapproved drugs; however the expanded access program does not address this concern. ${ }^{119}$ Right-to-try varies in how it addresses liability depending upon state law, but generally it bars actions by medical licensing boards from pursuing a physician who proscribed or recommended an investigational drug. ${ }^{120}$ Many states also include additional protection for the manufacturer of the drug. ${ }^{121}$

The most notable differences between the two options are the timeframe and who regulates the process. Expanded access could potentially take only hours if the patient is able to apply for an emergency IND, but it could take days. ${ }^{122}$ Through the more common non-emergent IND, there is a thirty-day window that the patient could have to wait before receiving approval. ${ }^{123}$

Right-to-try, however, is based on the premise of getting the patient access to the drugs they need with no delay. Additionally, right-to-try allows a single physician to grant access by giving a patient a prescription for an experimental drug (assuming the manufacturer agrees to provide the drug) leaving the physician with the exclusive right to decide if a patient should be granted access. ${ }^{124}$ One the other hand,

11821 C.F.R. $\$ 312.8(\mathrm{c})$ (2016). see also Holbein et al., supra note 39, at 527; see also Right to Try Model Legislation, supra note 111.

119 See 21 C.F.R. 312 (2016); see also Holbein et al., supra note 39, at 527; see also Right to Try Model Legislation, supra note 111.

${ }^{120}$ See 21 C.F.R. 312 (2016); see also Holbein et al., supra note 39, at 527; see also Right to Try Model Legislation, supra note 111.

${ }^{121}$ Holbein et al., supra note 39, at 527.

122 See 21 C.F.R. 312 (2016); see also Holbein et al., supra note 39, at 527; see also Right to Try Model Legislation, supra note 111.

${ }^{123}$ See 21 C.F.R. 312 (2016); see also Holbein et al., supra note 39, at 527; see also Right to Try Model Legislation, supra note 111.

124 Trasatti \& Grago, supra note 40, at 325. 
expanded access requires FDA approval and more oversight and regulation. ${ }^{125}$ Nevertheless, that does not mean right-totry is left without any oversight as it still requires Phase One testing to be successfully completed and safety is the main emphasis of this phase. ${ }^{126}$

\section{INDIANA's RIGHT-TO-TRY LAW}

On March 24, 2015, Governor Mike Pence signed House Bill 1065 into law, which allows terminally ill patients the right-to-try investigational drugs when certain criteria are met (criteria discussed below). ${ }^{127}$ The right-to-try law aims to allow terminally ill patients greater access to the use of experimental drugs, not yet approved by the FDA, which could potentially save their lives. ${ }^{128}$ Specifically, the law permits a drug manufacturer to make available to patients the use of investigational or experimental drugs, biological products, or medical devices that have successfully completed Phase One of the FDA approval process but have not been approved for general use and remain in clinical trials. ${ }^{129}$

In order for a patient to qualify, they must consent to the treatment and meet several criteria before they can obtain the experimental treatment or drug. ${ }^{130}$ The patient must be examined by a licensed physician who has agreed to treat them. ${ }^{131}$ The physician must: (1) determine there is no

${ }^{125} \mathrm{Id}$.

${ }^{126}$ The FDA's Drug Review Process: Ensuring Drugs Are Safe and Effective, supra note 22.

${ }^{127}$ Firger, supra note 2; In Your State, Indiana, RIGHTTOTRY.ORG, http://righttotry.org/in-your-state/indiana/ [https://perma.cc/AE33EJE5] (last visited March 28, 2017).

${ }_{128}$ IND. CODE § 16-42-26-2 (2015); See Firger, supra note 2; See also H.B. 1065, $119^{\text {th }}$ Gen. Assemb., First Reg. Sess. (Ind. 2015).

${ }^{129}$ IND. CODE $§ 16-42-26-2$ (2015).

${ }^{130}$ IND. CODE § 25-22.5-1-2.1 (2017).

${ }^{131} \mathrm{Id}$. 
reasonable basis for a conclusion that if the patient were administered the medical treatment as directed, that it would pose an unreasonable and significant risk of danger to them; (2) determine the individual has been diagnosed with a terminal illness and has no comparable or satisfactory treatment options that have been approved by the FDA available to them, and the probable risk that the patient might incur from the experimental or nonconventional treatment is not greater than the probable risk the patient faces from their existing disease or condition; and (3) provide the patient with a written statement, in addition to an oral explanation, that explains the treatment the patient is seeking. ${ }^{132}$

The statement must be signed by the patient or their legal representative and include: (1) that the treatment is experimental or nonconventional; (2) that there has been no FDA approval of the drug; (3) the material risks of the treatment side effects that a reasonably prudent physician would recognize; and (4) an explanation of the patient's expected medical treatment, which should include the frequency and the duration of the treatment that the patient will be receiving. ${ }^{133}$ However, the law does not create a cause of action against a health care provider, who is involved in the use of an investigational drug, biological product, or device, if the patient is harmed by the treatment, nor does the law create a cause of action against a manufacturer of the drug. ${ }^{134}$

Overall, Indiana's right-to-try law is similar to the FDA's expanded access program, but is more "watereddown" when it comes to regulation. Both processes allow patients access to the same drugs which have completed Phase One of the FDA approval process. Indiana's law

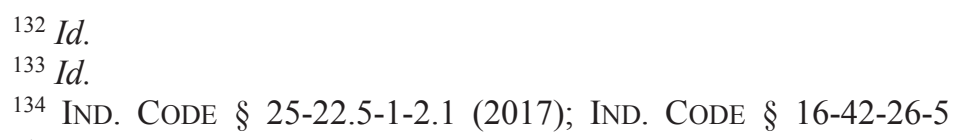


essentially removes the FDA as a regulator. ${ }^{135}$ While the law requires that a patient provide their informed consent, all other safety measures in place in the FDA's expanded access program, such as IRB and FDA approval, are not required. Essentially, the right-to-try should make the process as simple as a patient receiving authorization from their doctor, and then asking the drug manufacturer for access to the experimental drug.

\section{A. Other States on Right-to-Try}

Indiana is not the only state to pass right-to-try legislation. In fact, twenty-four other states have passed similar legislation, and at least twenty-three other states have introduced right-to-try legislation. ${ }^{136}$ The President of the Goldwater Institute, an Arizona-based conservative and libertarian public policy think tank established in 1988, stated that the notion that the "right to try is sweeping the country may be an understatement." 137 She explained, "[i]n just 15 months the law has been adopted in 23 states. Americans are united in the belief that when your morality hangs in the balance, you should have the right to try to save your life." 138 The Goldwater Institute created model legislation that many states have adopted or adapted in

${ }^{135}$ Cf. Trasatti \& Gargo, supra note 40, at 327.

${ }^{136}$ About Right to Try, supra note 1 . Since writing this note, but prior to publication, nine more states have passed right-to-try legislation.

${ }^{137}$ Michael Bologna, Illinois Becomes 23 'Right-to-Try' State, BLOOMBERG L. (Aug. 21, 2015), https://www.bloomberglaw.com/search/results/a7d9898e59bbec107562 a461a7eb95bc/document/X5JFF8PC000000?search32=IpmohMK1a1s 41NaosYTC0Q\%3D\%3DXfx0eYCWDEptB2C_hv5tiDSKIB3ukXk2YUk_BnpxecOyybcZnhN̄Uv2OEawTCCrYYzjEeMB_qCOaiv2TJYgXtNd60Ud8Gf2Yu2Ki 4WWDWA\%3D, [https://perma.cc/3V9D-YHF4].

${ }^{138}$ Id. 
enacting their own right-to-try legislation. ${ }^{139}$ The use of this model legislation has led to very little variation in state rightto-try laws, and their over-riding theme is generally the same. ${ }^{140}$ Due to this uniformity, each state law faces similar limitations.

\section{Colorado}

On May 17, 2014, Colorado became the first state to pass a right-to-try act when Governor John Hickenlooper signed a Right to Try bill into law. ${ }^{141}$ The Act defines an eligible patient as one with a terminal illness, meaning "a disease that, without life-sustaining procedures, will soon result in death or a state of permanent unconsciousness from which recovery is unlikely." 142 Written informed consent is required from the patient, and must be attested to by the patient's physician and a witness, prior to beginning treatment. ${ }^{143}$ The Act includes criteria that informed consent must make it clear to patients the treatment and its associated risks that they will be choosing to undergo. ${ }^{144}$ The Act does not require an insurer or provider to pay for an eligible patient's treatment or any subsequent care that result as a consequence of the use of the experimental drug. ${ }^{145}$ Insurers may also deny coverage to an eligible patient once they begin using an experimental drug until up to six months from

139 See Right to Try Model Legislation, supra note 111.

${ }^{140}$ Rubin, supra note 59.

${ }^{141}$ Patti Parson, Colorado first state to pass 'Right to Try,' or the 'Dallas Buyers' Club' law, PBS NEWSHOUR (May 19, 2014, 2:11 PM), http://www.pbs.org/newshour/rundown/colorado-first-state-passright-try-dallas-buyers-club-law/ [http://perma.cc/GNP5-FK8S].

${ }^{142}$ Colo. Rev. STAT. § 25-45-103 (2016).

${ }^{143} \mathrm{Id}$.

${ }^{144} \mathrm{Id}$.

${ }^{145}$ Colo. Rev. Stat. § 25-45-104 (2016). 
when the product is no longer used by the patient. ${ }^{146}$ Additionally, the Act does not require a manufacturer to make their product available and allows them to provide their product with or without receiving compensation from the patient for the costs associated with the manufacturer of the product. ${ }^{147}$

Regarding liability, the Act does not create a cause of action against a health care provider's license or Medicare certification, and the licensing board may not "revoke, fail to renew, suspend, or take any action against a health care provider's license" based only on their recommendation of a patient's access to an experimental treatment, as long as the recommendation was consistent with medical standards of care. ${ }^{148}$ Additionally, no cause of action is created against a manufacturer of an investigational product or any person or entity that is involved in the eligible patients care, for any harm caused by the product, as long as there has been good faith compliance with the act and reasonable care was exercised. ${ }^{149}$

\section{Texas}

Texas was one of the more recent states to pass right-totry legislation. Governor Greg Abbott signed the state's right-to-try act into law in June of 2015. ${ }^{150}$ The Act requires that the patient have a terminal illness, which their treating physician will attest to, to be considered an eligible

${ }^{146} I d$.

${ }^{147} \mathrm{Id}$.

${ }^{148} I d$. $\S 25-45-105$ (2016).

${ }^{149} I d$. § 25-45-107 (2016).

${ }^{150}$ Starlee Coleman, Texas Becomes $21^{\text {st }}$ State to Allow Terminally Ill to Access Investigational Medications, GOLDWATER INST., http://goldwaterinstitute.org/en/work/topics/healthcare/right-totry/texas-becomes-21st-state-to-allow-terminally-ill-t/ [http://perma.cc/SW9K-PZWR] (last visited Jan. 7, 2016). 
patient. ${ }^{151}$ The patient's written informed consent is also required. ${ }^{152}$ The Act allows manufacturers to make their experimental drugs available to eligible patients, but does not require them to make their products available. ${ }^{153}$ If the manufacturer makes available an investigational drug to the patient, they must do so without receiving compensation. ${ }^{154}$ The Act also authorizes health benefit plans to pay for coverage, but does not require payment. ${ }^{155}$ Additionally, the Act covers civil liability and prevents any private or state cause of action from being created against a manufacturer or "against any other person or entity that is involved in the care of an eligible patient ... for any harm done to the eligible patient resulting from the investigational drug." 156 The Texas Medical Board also may not "revoke, fail to renew, suspend, or take any action against a physician's license... based solely on the physician's recommendations to an eligible patient regarding access to or treatment with an investigational drug" provided that the care and recommendation the physician provided met the medical standard of care. ${ }^{157}$

Another interesting aspect of Texas' Act is that it uses the language of classifying right-to-try as a fundamental right. The Act states, "patients with a terminal illness have a fundamental right to attempt to pursue the preservation of their own lives by accessing available investigational drugs, biological products, and devices." 158

${ }^{151}$ Tex. Health \& Safety Code $\S 489.051$ (2015).

${ }^{152} I d . \S 489.052$.

${ }^{153} I d . \S 489.053$.

${ }^{154} \mathrm{Id}$.

${ }^{155}$ See Id. $\S 489.101$; H.B. 21, $84^{\text {th }}$ Legislature, (Tex. 2015).

${ }^{156} \mathrm{Id}$. $\S 489.054$.

${ }^{157}$ Id. $\S 489.151$.

${ }^{158}$ H.B. 21, 84 $4^{\text {th }}$ Legislature, (Tex. 2015). However, since writing this note, but prior to publication, Texas enacted TEX. HEALTH \& SAFETY CODE $§ 489.051$ et seq. which no longer contains this language. 


\section{Michigan}

Two of Indiana's border states have also passed right-totry legislation, but legislation has only been introduced in Ohio and Kentucky. In October of 2014, Michigan Governor Rick Snyder signed right-to-try into law. ${ }^{159}$ Michigan requires that patients who seek the right-to-try have an advanced illness, which is defined as "a progressive disease or medical or surgical condition that entails significant functional impairment, that is not considered by a treating physician to be reversible even with administration of current federal drug administration approval and available treatments, and that, without life-sustaining procedures, will soon result in death." 160 The State also requires that the patient give written, informed consent prior to use. ${ }^{161}$ The law also provides that the patient's health plan or third party provider is not obligated to pay for the experimental drug, but may provide coverage if they choose to do so. ${ }^{162}$ It also does not require that manufacturers provide the drug that the patient requests. ${ }^{163}$ If the manufacturer decides to provide the drug, they may do so at no charge, or require the patient to pay the costs for manufacturing of the drug. ${ }^{164}$

In regards to liability, the Act:

does not create a private cause of action against a manufacturer . . . or against any person or entity that is involved in the care of

${ }^{159}$ Nick Gillespie, Michigan Gov. Rick Snyder Signs "Right to Try" Law; a Win for Patient, REASON.COM (October 21, 2014 10:59 AM) https://reason.com/blog/2014/10/21/michigan-gov-rick-snyder-signsright-to [perma.cc/H7SA-7KPV].

${ }^{160}$ MicH. COMP. LAWS $\S 333.26451$ (a) (2015).

${ }^{161} \mathrm{Id}$.

${ }^{162} I d . \S 333.26453$.

${ }^{163} I d . \S 333.26452$.

${ }^{164} \mathrm{Id}$. 
an eligible patient using the investigational drug . . . for any harm done to the eligible patient resulting from the investigational drug . . . if the manufacture or other person or entity is complying in good faith with the terms of the act and has exercised reasonable care. ${ }^{165}$

The licensing board or disciplinary subcommittee may also "not revoke, fail to renew, suspend, or take any action against a health care provider's license" based on the provider's recommendation that a patient receive access to an experimental drug. ${ }^{166}$

\section{Illinois}

Governor Bruce Rauner signed into law House Bill 1335 on August 5, 2015, also known as Right to Try Act. ${ }^{167}$ The Illinois Act defines an eligible patient as one who has a terminal illness, has considered all FDA approved treatment options, was recommended an investigational treatment option by his or her physician, has given written informed consent to use the investigational treatment, and has documentation from his or her physician indicating the requirements of this Act have been met. ${ }^{168}$ Terminal illness is defined as "a disease that, without life-sustaining measures, can reasonably be expected to result in death in 24

${ }^{165}$ Id. $\S 333.26457$.

${ }^{166}$ Id. $\S 333.26455$.

167 Heather Weiner, Rauner Signs Law Allowing 'Right to Try' Experimental Drugs, ILl. POLICY Inst. (Aug. 5, 2015) https:/www.illinoispolicy.org/right-to-try-passes-in-illinois/ [http://perma.cc/REM9-2DFG].

168410 ILl. COMP. STAT. 649/10 (2016). 
months or less."169 The Act does not require that drug manufacturers make their products available and allows the manufacturer to decide whether to charge the patient for the treatment if they decide to make it available. ${ }^{170}$ Insurers are not required to cover the cost of the experimental treatment. ${ }^{171}$ The Illinois law also uniquely requires that "[a]ny official, employee, or agent of the State who blocks or attempts to block access by an eligible patent to an investigational drug" will be guilty of a misdemeanor and could be punished with a fine of up to $\$ 1,500 .{ }^{172}$ Right-totry supporters would likely find this fine to be a great protection. However, supporters may be disappointed with the lack of protections for physicians not found in the Illinois statue. ${ }^{173}$

\section{B. How Does Indiana Compare?}

State right-to-try laws seem to see the most variation when it comes to who is an eligible patient and issues of civil liability. Indiana's right-to-try act differs from other states in that instead of defining an eligible patient, it lays out requirements an individual must meet in order to request an experimental drug and be considered a qualified patient. ${ }^{174}$ First, the individual must give informed consent. Next, the

${ }^{169} \mathrm{Id}$

${ }^{170}$ Id. 649/15 (2016).

${ }^{171}$ Id. $649 / 20(2016)$.

172 Id. 649/25 (2016).

173 See H.B. 1335, 99 ${ }^{\text {th }}$ Gen. Assemb. (Ill. 2015). The bill prevented the Department of Financial and Professional Regulation from revoking, suspending, placing on probation, or refusing to issue or renew, or any other disciplinary action against the physician's license because that physician recommended an eligible patient for an experimental drug. However, since writing this note, but prior to publication, this statute was enacted but no longer contains this language.

${ }^{174}$ IND. CODE $§$ 25-22.5-1-2.1 (2017). 
treating physician must either determine that "there is no reasonable basis to conclude that the medical treatment, when administered as directed, poses an unreasonable and significant risk of danger to the individual receiving the medical treatment;" or the individual has been diagnosed with a terminal disease or condition and has no other satisfactory treatment options with FDA approval available to them and the "probable risk to the individual from the experimental nonconventional medical treatment is not greater than the probable risk from the individual's disease or condition." 175 The physician must also provide the individual with a written statement and oral explanation of the treatment they will receive. ${ }^{176}$ This requirement for access to experimental drugs is unique when compared to some other state laws. ${ }^{i}$ Indiana's requirements are very similar to the FDA's expanded access program requirements. ${ }^{177}$ These more stringent requirements may make it harder for Indiana patients to gain access to experimental drugs than patients in states where eligible patient is defined less strictly. Therefore, Indiana's law may not be as effective in expanding access as other state laws may be.

While Indiana chooses to follow criteria very similar to the FDA's expanded access program's requirements when deciding if a patient may access experimental treatments, other states use differing requirements. For example, in California's Right to Try Bill, an eligible patient is defined as someone who "has a terminal disease determined by that person's physician and a consulting physician." ${ }^{178}$

\footnotetext{
${ }^{175} \mathrm{Id}$.

${ }^{176} \mathrm{Id}$.

${ }^{177}$ See generally Expanded Access (Compassionate Use), supra note

${ }^{178}$ CAL. Heal TH \& SAFETY 111548.1(b) (2016); See Governor Jerry Brown Protects Patients By Vetoing California's Right-To-Try Bill,
} 12. 
Therefore, two physicians must agree that the patient is terminally ill. Terminal disease is defined as "an incurable and irreversible disease that has been medically confirmed and will, according to reasonable medical judgment, result in death within six-months of diagnosis." 179 However, Colorado's law only requires death to be soon, rather than a six-month requirement. ${ }^{180}$ Similarly, Michigan requires an advanced illness that will soon result in death without treatment. ${ }^{181}$ Alternatively, Illinois requires that a patient be terminally ill and whose death is likely within twenty-four months if no treatment is received. ${ }^{182}$ Texas also requires a terminal illness, but does not have the twenty-four month requirement. ${ }^{183}$ States like Michigan define eligible patients under a broader and more inclusive scope. ${ }^{184}$ The broader the state's eligibility criteria, the more patients will potentially have access to experimental drugs. States with stricter criteria, like Indiana, put more limitations on whether terminal patients can gain access to experimental drugs.

Like most other states, Indiana's Act does not require that an insurer or provider pay for the experimental treatment and allows the manufacturer to choose if they wish to

SCIENCE BLogs, (Oct.13, 2015), http://scienceblogs.com/insolence/2015/10/13/governor-jerry-brownprotects-patients-by-vetoing-californias-right-to-try-bill/

[http://perma.cc/3KMJ-WTRN] (explaining that Governor vetoed California's bill and supported the FDA compassionate use program instead. Supporters are now lobbying the legislature to override the governor's veto).

${ }^{179}$ CAL. Health \& SAFETY 111548.1(d) (2016).

${ }^{180}$ COLO. REV. STAT. § 25-45-103 (3) (2015).

${ }^{181}$ Mich. COMP. LAWS ANN. § 333.26451 (LexisNexis 2015).

182410 ILL. COMP. STAT. 649/10 (2016).

183 Tex. Health \& Safety Code AnN. § 489.051 (LexisNexis 2015).

${ }^{184}$ Mich. Comp. Laws ANN. § 333.26451 (LexisNexis 2015). 
provide their product to a qualified patient or not. ${ }^{185}$ This policy may make the group of eligible patients that may benefit from the Act even smaller and does not help to enhance expanded access. While the Act may give patients the right to try the experimental drug, it cannot force the manufacturer to hand the drug over to the patient.

Another major variance in state right-to-try laws is who is immune from civil liability. Indiana's Act is similar to other states in that it does not create a cause of action against the health care provider. ${ }^{186}$ However, some states, in their right-to-try acts, provide that there may be no cause of action against the manufacturer or physician, while other states only provide liability for one or the other or neither. Indiana's act protects both the physician and manufacturer from liability. ${ }^{187}$ Colorado, Texas, and Michigan also choose to shield both the physician and the manufacturer from civil liability. ${ }^{188}$ Alternatively, in Illinois, physicians and manufacturers are both left vulnerable to civil liability, as the law currently remains silent as to liability. ${ }^{189}$ This These protections are likely a strength to Indiana's law, as physicians and manufactures may feel reluctant to provide experimental drugs, but with protection from civil liability they may feel some security.

${ }^{185}$ IND. CODE ANN. § 25-22.5-1-2.1 (2017); IND. CODE ANN. § 1642-26-4 (2017).

186 Id.

187 Id.

${ }^{188}$ COLO. Rev. STAT. § 25-45-107 (2015); TeX. HeAlth \& SAFETy Code ANN. § 489.054 (LexisNexis 2015). ); Mich Comp. Laws ANN. § 333.26457 (LexisNexis 2015).

189410 ILl. COMP. STAT. 649/1 et seq. (2016). 


\section{LIMITATIONS ON RIGHT-TO-TRY}

Those who oppose right-to-try legislation have called the state laws "placebo legislation," 190 as their expected usefulness in expanding patient access is questionable due to several limitations. These limitations are so strong, they are likely to diminish how effective state right-to-try laws will be in expanding access to patients. Therefore, Indiana's law may not actually have the desired effect of expanding access.

\section{A. Drug Manufacturers Are Not Required to Provide Patient Access}

The FDA is not legally able to require that a drug manufacturer provide, or make available, their drug to a patient who seeks access. ${ }^{191}$ Similarly, Indiana's right-to-try law does not require that any person or organization provide patients with access, coverage, or to make a payment for a medical treatment that is not otherwise commercially available to them. ${ }^{192}$ This includes insurers, the fraternal benefit society, nonprofit corporations, health maintenance organizations, preferred provider agreements, or limited service health maintenance organizations. ${ }^{193}$

Manufacturers are also not required to manufacture more of a drug to meet a larger patient need. ${ }^{194}$ Manufacturers can choose to deny a patient's right-to-try request as they have no obligation to provide the drug. ${ }^{195}$ Their reasoning may stem from their limited supply of a drug or concern for

190 Yang, supra note 3, at 2598.

${ }^{191}$ Rubin, supra note 59.

192 Ind. Code Ann. § 25-22.5-1-2.1 (2017).

${ }^{193} \mathrm{Id}$.

${ }^{194}$ Holbein, supra note 39, at 528.

195 Jacob, supra note 60, at 759; See also Christopher H. Leu et al., Right to Try?, 13 J. CLINICAL OnCOLOGY 1518, 1518 (2014). 
providing the medication outside of a clinical trial. ${ }^{196}$ Manufacturers may fear that if patients can receive the drug outside of a clinical trial, they may be less likely to enroll, especially when enrolling could mean they can avoid the risk of being placed in the placebo group. ${ }^{197}$ Adverse reactions are another major concern, as they can jeopardize the chances of drug approval. ${ }^{198}$

B. Insurance Companies Are Not Required to Cover, or Contribute to, the Cost of the Experimental Drugs

Additionally, state right-to-try laws do not place any legal obligations on insurers to pay for experimental treatments. ${ }^{199}$ Normally, insurers will exclude coverage for experimental drugs or unapproved treatments. ${ }^{200}$ This limitation creates issues of fairness as some patients will be able to afford access, but many will still be limited in that even though they have the right to access the drug, they will not be able to afford that access. Terminally ill patients, therefore, may be able to obtain the right to try experimental drugs via right-to-try laws, but may lack the financial means necessary to actually purchase the drug. ${ }^{201}$

Furthermore, there is no legal guarantee that even if a patient is able to obtain an experimental drug through rightto-try, that their insurance will cover the cost of the drug, administration, follow-up, or management of potential adverse effects. ${ }^{202}$ Patients also incur the risk of potentially losing their insurance coverage for up to six months after the

\footnotetext{
196 Jacob, supra note 60, at 759.

${ }^{197}$ Id.

${ }^{198} I d$.

199 Yang, supra note 3, at 2598.

${ }^{200} \mathrm{Id}$.

${ }^{201} \mathrm{Id}$.

${ }^{202}$ Leu, supra note 198, at 1518.
} 
time in which they used the investigational drug. ${ }^{203}$ This means if the patient were to need coverage, hospice care or home health services, they may be unable to get coverage for some time after using the experimental drug. ${ }^{204}$ This risk is not one a terminally ill patient can take lightly, and therefore must weigh the costs and risks before making the decision to try to obtain an investigational drug. ${ }^{205}$

For example, after the right-to-try was passed in Colorado, Amyotrophic Lateral Sclerosis (ALS) patients began inquiring about undergoing an experimental stem cell therapy procedure that was undergoing clinical trials. ${ }^{206}$ However, none of the patients who inquired decided to go through with the treatment as it was going to cost them up to $\$ 100,000$, and existing data was not yet conclusive enough to know for sure if the treatment would be effective. ${ }^{207}$ Therefore, patients may have decided to forgo treatment due to the expense of the drug without insurance to help cover the cost and protect them from the risk.

\section{Fairness}

Fairness is another issue that right-to-try legislation may face. Individuals who are not the most knowledgeable in promoting their case, lack connections, or lack funds to afford expensive treatments, may be at a disadvantage when it comes to accessing experimental drugs outside of the clinical trial process. ${ }^{208}$ This means drugs may go to the

\footnotetext{
${ }^{203} I d$.

${ }^{204} I d$.

${ }^{205} \mathrm{Id}$.

206 Jacob, supra note 60, at 758 .

${ }^{207} \mathrm{Id}$.

${ }^{208} \mathrm{Id}$. at 760 .
} 
patient who is savvier, rather than the patient who is the sickest or the best candidate to be receiving the treatment. ${ }^{209}$

Additionally, right-to-try laws involve a subjective determination made by the physician, as they hold the sole discretion of deciding who qualifies for access, which could lead to inconsistencies in application. ${ }^{210}$ While one physician might grant a patient access, a physician somewhere else might deny that same patient access. This broad discretion could encourage patient forum shopping and misconduct by physicians. ${ }^{211}$

\section{Possibility of Federal Preemption}

Perhaps the most crucial limitation that Indiana and other state right-to-try legislation may face is the possibility of federal preemption. It appears likely that the FDA could supersede these attempts by state policymakers if they decided to challenge right-to-try legislation. ${ }^{212}$ If this happened, right-to-try laws could be struck down if they conflict with federal law or FDA regulations. ${ }^{213}$ This is true because according to the Supremacy Clause of the United States Constitution, when state laws conflict with federal law the state law is invalid. ${ }^{214}$ The FDA has not yet attempted to challenge state law, but there is reason to believe that state right-to-try laws will be unable to increase drug companies' willingness to provide patients with experimental drugs. ${ }^{215}$ Companies have reason to worry that the FDA could take

209 Id.

${ }^{210}$ Trasatti \& Grago, supra note 40, at 328.

211 Id.

212 Yang, supra note 3, at 2598.

${ }^{213} \mathrm{Id}$.

${ }^{214}$ U.S. CONST. art. VI, cl. 2.

${ }^{215}$ Rebecca Dresser, "Right to Try" Laws: The Gap between Experts and Advocates, 45 HASTINGS CTR. REPORT 9, 10 (May-June 2015). 
legal action against them for providing experimental drugs without permission. ${ }^{216}$

\section{Federal Right-TO-Try Legislation}

The right-to-try is also receiving attention at the federal level, which could help to solve the limitation of federal preemption. If the federal government decides to pass legislation on right-to-try, it could ensure that states that have passed their own right-to-try laws will be able to take full advantage of them without fear of backlash from the FDA.

\section{A. Right to Try Act of 2015}

On July 9, 2015, three House Republicans introduced a Bill, H.R. 3012, that, if passed, would apply to the states that have already passed their own right-to-try laws. ${ }^{217}$ The purpose of the federal bill is to eliminate potential conflict between state laws and federal regulations and would prevent the FDA from taking action to stop a patient's access to experimental drugs. ${ }^{218}$ The bill could prohibit the federal government from acting in a way to prevent terminally ill patients from obtaining this access to drugs via their state right-to-try laws. ${ }^{219}$

The bill, also known as "Right to Try Act of 2015," would "authorize the use of unapproved medical products by

${ }^{216} I d$.

217 James C. Shehan, The Right to Try Act of 2015 - A Serious Challenge to FDA Control of Expanded Access?, FDA BLOG (July 13, 2015),

http://www.fdalawblog.net/fda_law_blog_hyman_phelps/2015/07/theright-to-try-act-of-2015-a-serious-challenge-to-fda-control-ofexpanded-access-.html [http://perma.cc/W9QJ-LAXV].

${ }^{218}$ Right to Try Act of 2015, H.R. 3012, $114^{\text {th }}$ Cong. (2015-2016).

${ }^{219}$ Shehan, supra note 220. 
patients diagnosed with a terminal illness in accordance with state law, and for other purposes." 220 The bill would prevent the federal government from taking action to prohibit or restrict "the production, manufacture, distribution, prescribing, dispensing, possession, or use of an experimental drug, biological product, or device," that "is intended to treat a patient who has been diagnosed with a terminal illness; and is authorized by, and in accordance with, State law."221

Like Indiana's right-to-try law, this federal legislation would require that the experimental product was successful in its completion of Phase One of a clinical trial. ${ }^{222}$ Representative Stutzman sees this law as being complementary to state right-to-try laws, in that this new federal law may help with some of the reluctance companies are feeling about violating regulations requiring prior FDA approval when deciding whether to allow terminally ill patients access to their experimental drugs. ${ }^{223}$ This new federal legislation could help to further expand access and help patients utilize their state right-to-try laws that are not being regularly used. ${ }^{224}$ However, this is not the only hopeful federal legislation for terminally ill patients on the horizon.

\section{B. Andrea Sloan CURE Act}

On December 8, 2014, H.R. 5805 "Andrea Sloan Compassionate Use reform and Enhancement Act" or the "Andrea Sloan CURE Act," was introduced into Congress. ${ }^{225}$ The bill would amend Section 561 of the

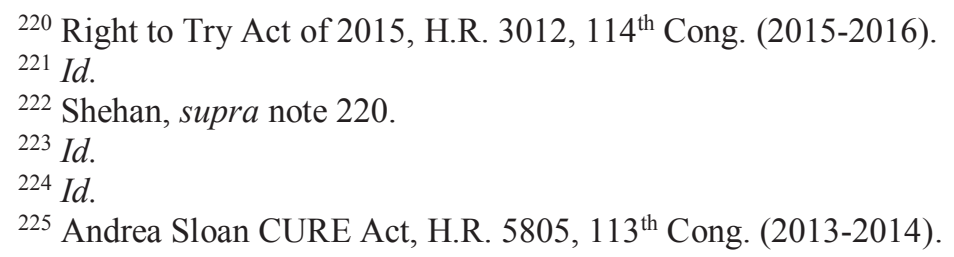


Federal Food, Drug, and Cosmetic Act and is meant to supplement the FDA's expanded access (compassionate use) program. ${ }^{226}$ The bill would require that drug companies provide the FDA and patients with more information about the process for dealing with requests for expanded access. ${ }^{227}$ The bill has five major provisions.

First, within thirty days after a drug meets the definition of a covered breakthrough drug, the drug sponsor must submit to the FDA their policy for requests and make the information publicly available. ${ }^{228} \mathrm{~A}$ covered breakthrough drug is defined as a drug

[T] hat is designated as a breakthrough therapy or as a fast track product or is approved under accelerated approval under section 506; [] that is designated under section $505 \mathrm{E}(\mathrm{d})$ as a qualified infectious disease product; or [] the sponsor of which is awarded a priority review voucher under section 524 or $529 .{ }^{229}$

If the sponsor decides to accept requests for the drug, their policy must include four criteria. ${ }^{230}$ First, there must be a single point of contact that will receive and process requests. ${ }^{231}$ Second, there must be procedures in place for such requests. ${ }^{232}$ Third, the policy must include the criteria minimally necessary for the sponsor's consideration or

$$
\begin{aligned}
& { }^{226} \mathrm{Id} \text {. } \\
& { }^{227} \mathrm{Id} \text {. } \\
& { }^{228} \mathrm{Id} \text {. } \\
& { }^{229} \mathrm{Id} \text {. } \\
& { }^{230} \mathrm{Id} \text {. } \\
& { }^{231} \mathrm{Id} \text {. } \\
& { }^{232} \mathrm{Id} \text {. }
\end{aligned}
$$


approval of requests. ${ }^{233}$ Last, there must be a time frame for which the sponsor anticipates will be necessary for decision making on the requests. ${ }^{234}$

The bill's second provision requires, if a manufacturer or distributor chooses to deny requests for expanded access, they must submit to the person who made the request written notice of denial within five days and must include an explanation for the denial. ${ }^{235}$

Third, the Government Accountability Office is required, within 180 days (and subsequent years if the bill shall pass) of enactment, to submit a report to Congress that analyzes the current expanded use program and "the extent to which . . . patients have access to investigational drugs pursuant to . . . 21 U.S.C. 360bbb."236 The report must include recommendations for improving access and qualitative analysis accessing each of the listed factors. ${ }^{237}$

Fourth, the bill establishes a nine member Expanded Access Task Force that will provide recommendations to help improve the program. ${ }^{238}$ The task force would be required to submit a report to Congress, within 180 days after it has convened. ${ }^{239}$

Lastly, the bill would require that the FDA finalize its draft expanded access guidance. ${ }^{240}$ "The bill [will] not preempt [any] state right to try laws." 241 The passage of the

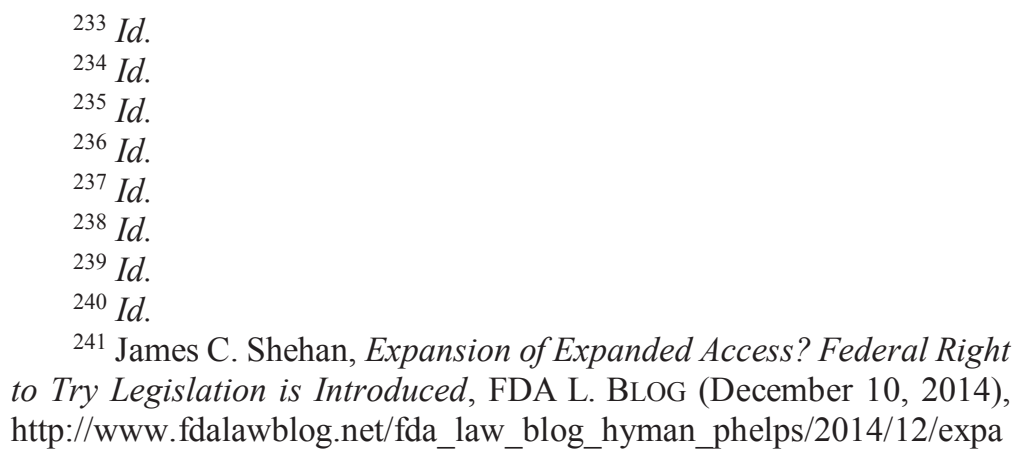


bill is not expected to be quick, and Congressman Michael McCaul, a sponsor of the bill, "plans to re-introduce [it] . . . in the next Congress. ${ }^{242}$

\section{How Limitations WiLl IMPACT A PATIENT'S RIGHT-TO-TRY}

As of January of 2015, a reporter for the New York Times was unable to locate any cases where terminally ill patients were able to access experimental drugs, without FDA permission, using right-to-try laws. ${ }^{243}$ While stories of states passing right-to-try laws are prominent, stories of patients actually utilizing their state's law are scarce. State right-totry legislation may offer patients seeking experimental drugs hope for a cure, but the laws may not actually be practical in their ability to get these drugs to the patient.

State laws will fail to substantially alter patient's abilities to access drugs due to the many limitations the laws face. ${ }^{244}$ Nationwide, state right-to-try laws will likely not lead to a meaningful change as FDA regulations prevent companies from providing their drugs to terminally ill patients, and state law will not be enough to protect these companies from federal liability. ${ }^{245}$

\footnotetext{
nsion-of-expanded-access-federal-right-to-try-legislation-isintroduced.html [http://perma.cc/RF96-AM7N].

${ }^{242} \mathrm{Id}$.

${ }^{243}$ Dresser, supra note 218, at 10.

${ }^{244}$ Sam Adriance, Fighting for the "Right to Try" Unapproved Drugs: Law as Persuasion, 124 THE YAle L.J. Forum 148, 152-55 (Dec. 4, 2014 , http://www.yalelawjournal.org/pdf/AdriancePDF_vdkbnz4m.pdf [http://perma.cc/PK4S-MUWX].

${ }^{245} I d$.
} 


\section{A. Impact on Indiana Patients}

Indiana's right to try law will likely not be able to achieve terminally ill patients' desired outcome as it is unlikely to lead directly to the expansion of access. Similar to other state laws, there are too many limitations in the way of Indiana's right-to-try law being able to expand access. While the FDA still has regulatory control, drug companies may fear the consequences of providing experimental drugs outside an approved FDA process. Additionally, as the law does not require action by either insurers or manufacturers, patients may have an even harder time gaining access to experimental drugs.

Indiana's law also faces some further limitations that some states may not have to deal with. Right-to-try in Indiana fails to provide manufacturers with protection from civil liability if the patient were to be harmed by the experimental drug. Many states offer this protection. Drug manufacturer's hesitance to comply with right-to-try creates an even bigger obstacle. ${ }^{246}$ Patients may have an even harder time convincing drug manufacturers to let them try experimental drugs if they have to fear civil liability.

Also, Indiana's right-to-try law provides a very narrow definition for what a patient must do to be considered a "qualified patient," prior to being able to request an experimental drug. Like the FDA's expanded access program, Indiana sets requirements for how much risk a patient may assume when deciding to take an experimental drug. By narrowing the criteria for inclusion of qualified patients, there will be fewer patients able to take advantage of Indiana's law. If a terminally ill patient's risk from the experimental treatment is deemed greater than the risk from their medical condition, they will not be able to take the drug even if they agree to assume that risk. The physician has

${ }^{246}$ See generally, Yang, supra note 3, at 2598. 
great power to determine if a patient should be allowed to try an experimental treatment and to assess the risk involved. Due to these limitations, and the limitations impacting all state right-to-try laws, Indiana's law will likely not be very effective in expanding access.

\section{B. Hope for Future Expansion in access through Federal Legislation}

However, there is still hope for Indiana and other state right-to-try laws as they could serve as tools to help advocate for federal reform on the issue. ${ }^{247}$ Federal reform could take the form of a federal right-to-try law or possibly federal courts may decide to recognize (or decline to recognize) a right-to-try under the Constitution. ${ }^{248}$ As there are already several pieces of federal legislation in circulation, it is possible that soon this could be a reality.

State laws may also help to draw support for the issue, and help to draw the public's attention to the cause. ${ }^{249}$ Even though Indiana's right-to-try law may be largely ineffective for patients currently seeking access, it can still offer meaningful hope of future expanded access for future patients who face this struggle to access experimental drugs. The law may help to influence policy makers and help gather public support. State right-to-try laws may also help influence the pharmaceutical industry, the FDA, doctors, and other health care providers to work together to develop more efficient solutions for terminally ill patients. ${ }^{250}$

247 Adriance, supra note 247, at 155-57.

${ }^{248} \mathrm{Id}$. at 149 .

${ }^{249}$ Id. at 155-57; See also Thomas A. Hemphill, Is State 'Right to Try' Legislation Misguided Policy?, Regulation, Fall 2014, at 2, 3.

${ }^{250}$ Hemphill, supra note 252, at 2. 


\section{What if Federal Legislation Fails?}

If right-to-try legislation were to fail to pass on the federal level, all hope is not lost for patients seeking expanded access. The FDA's new draft guidance for expanded access, FDA 3926, appears to be very promising. The form should expedite the expanded access process, which is one of right-to-try advocates' greatest concerns with the previous expanded access form. If the FDA is able to speed up the process and keep up the high acceptance rate of patients who apply for access, this is a very positive alternative for terminally ill patients if federal legislation were to fall through.

\section{CONCLUSION}

Indiana, like other states, has made a step in the right direction in trying to expand terminally ill patients' access to investigational drugs. However, due to many limitations that state right-to-try laws may face, Indiana's attempt may still fall short in doing enough to expand access on its own. "Even if state laws are not preempted by federal legislation or FDA regulations, legal access based on state laws alone may not be enough." ${ }^{251}$ Federal legislation on right-to-try offers hope that the right could become a federally recognized right, which would expand access even more and allow states to start utilizing their own right-to-try laws without hesitation. While it may be unlikely that state rightto-try laws will result in improved access to experimental drugs and treatments on their own, ${ }^{252}$ with help from federal legislation, community support, and cooperation amongst health care providers and pharmaceutical companies,

\footnotetext{
251 Yang, supra note 3, at 2598.

${ }^{252} I d$.
} 
terminally ill patients may continue to see their options for expanded access increase.

Many of those who are the most vocal supporters of the right-to-try are terminally ill patients and their families as they have stories to tell about how a lack of access has impacted them. ${ }^{253}$ Their stories are prominent in the media and are very compelling. ${ }^{254}$ Often, after hearing these stories, lawmakers and the public feel "it would be cruel to vote against the right to try." ${ }^{255}$ These stories have helped to draw interest to the right-to-try cause, and it is hard not to empathize with these patients. ${ }^{256}$ However, stories of patients' gaining access to experimental drugs, without FDA permission, via their state right-to-try laws are virtually nonexistent, demonstrating what a strong impact the many limitations right-to-try faces are having on patients' ability to gain access. ${ }^{257}$ While there are areas that Indiana could itself improve its right-to-try law, such as by relaxing patient eligibility criteria, the State may also require help from federal legislation for the law to become widely functional. However, as the cause continues to grow there is hope that terminally ill patients will continue to see progress towards expanded access.

${ }^{253}$ Dresser, supra note 218 , at 10.

${ }^{254} I d$.

$255 I d$.

256 See Matt Smith, Five-Year-Old Indiana Boy to Lawmakers: 'Please Say Yes' to Right to Try Bill, FOX 59 (March 4, 2015, 4:52 PM). http://fox59.com/2015/03/04/indiana-boy-to-lawmakers-please-sayyes-to-right-to-try-bill/ [http://perma.cc/T3L4-JJD2] (Jordan McLinn, a five year old Indiana boy, is suffering from Duchenne muscular dystrophy. Id. His and his family's hope for a cure rests in experimental drugs and the right-to-try. Id. McLinn is fighting for his life and pleads his case before Statehouse committee members, asking them to please say yes to the right-to-try.) $I d$.

${ }^{257}$ Dresser, supra note 218, at 10. 